\title{
The Development of Scientific Research and Evaluation in Humanities and Social Sciences of German Universities
}

\author{
Lihong $\mathrm{Li}^{1,2,3, *}$ and Wanbing $\mathrm{Shi}^{4,5}$ \\ ${ }^{1}$ School of Humanities and Law Northeastern University \\ ${ }^{2}$ Liaoning Radio and TV University \\ ${ }^{3}$ Liaoning Vocational College of Equipment and Manufacture, Shenyang, China \\ ${ }^{4}$ Special Education Research Center \\ ${ }^{5}$ Nanjing Normal University of Special Education, Nanjing, China \\ *Corresponding author. Email: lilihong1127@sina.com
}

\begin{abstract}
Exploring the development of scientific research and evaluation in humanities and social sciences of German universities is of great value to improve the management of humanities and social sciences in China. This paper introduces and analyses the scientific research trend and evaluation system of humanities and social sciences in German universities and further clarify the reference and enlightenment of German university humanities and social science research to China's scientific research evaluation, aiming to provide international experience for the construction of humanities and social sciences research evaluation system in Chinese universities.
\end{abstract}

Keyword: Scientific research, Scientific evaluation, Humanities and social sciences, German universities.

\section{INTRODUCTION}

In 2020, China has issued a guideline to deepen the reform of education evaluation, which stressed adhering to scientific education evaluation and speeding up the modernization of education to establish a comprehensive Chinese and top-class evaluation system by 2035.The research on the evaluation of scientific research in Chinese universities started late, and the evaluation of scientific research indicators of humanities and social sciences in colleges and universities did not form a system, even still basically adopt the scientific research evaluation system of natural science This situation needs to be improved urgently. So we can learn some experience from German practices. Since the 1980s, Germany has gradually developed and formed self-evaluation of the university's scientific research evaluation system complemented by the government agencies (German Federal Ministry of Education and Research), and third parties (German Science Council, German Research Association, University Development Center, Humboldt Foundation of Germany). Changes in the scientific system over the last two decades, which include the introduction of instruments for assessing and managing research performance, have contributed to making differences in research performance more transparent and comprehensible. The British "Times Higher Education" published "German Research Rating: Winning by Quality" in April 2013 to evaluate the significance of the scientific evaluation of the German Science Council for academic research. [1] Thus studying the scientific research evaluation of humanities and social science in German universities will provide international experience for the construction of humanities and social sciences research evaluation in Chinese universities.

\subsection{The Development Trend of the Humanities and Social Sciences in German: Understanding Society-Shaping the Future. Bmbf Programme for the Humanities and Social Sciences (2019- 2025)}

The Federal Ministry of Education and Research $(\mathrm{BMBF})$ will further strengthen the potential of the humanities and social sciences to help equip society for 
the future. In the years to come, the 'Understanding Society - Shaping the Future' programme will intensify and expand support for the humanities and social sciences in three areas of focus:

\subsubsection{Mastering Social Challenges: Strengthening Research on Cohesion, Innovation and Cultural Heritage}

The societal upheavals and rapid technological developments currently taking place require new answers for how to shape the way we live together in Germany and how to strengthen our social cohesion. The federal government will strengthen social cohesion as a top priority. The BMBF will provide comprehensive support for research on preventing and restricting social radicalisation. The future research field will include migration and integration, Diversity and inequality. Innovative ideas for issues such as mobility, living, health, environmental protection and social coexistence increase our material and immaterial prosperity and help to overcome the challenges of the present and future. Innovation in education, science, civil society, politics, art, culture and administration will be urgently needed. This programme will strengthen the interdisciplinary research in the humanities and social sciences for cultural traditions, historical heritage and the historical foundations of cultural heritage.

\subsubsection{Creating Design and Development Freedom for Science}

Research in the humanities and social sciences, freedom primarily refers to time and an environment that promotes creativity, with the opportunity to ask scientifically motivated research questions and examine these issues. Small disciplines are of fundamental importance. Around 80 per cent of small disciplines can be found in the humanities, cultural sciences, social sciences and economics.

\subsubsection{Developing Research Data Infrastructures for Specific Needs}

Exceptional fundamental and application-oriented research on social problems requires efficient research data infrastructures as well as appropriately processed data. The fundamental principles for optimal dissemination and follow-up use of research data and findings are the FAIR principles (findable, accessible, interoperable, reusable). Research infrastructures need to be available for the full extent of research in the humanities and social sciences.[2]

From the above, we can see that the research in humanities and social sciences is playing an increasing role to the future. So the assessment and evaluation is correspondingly more important. Now let's analyze the evaluation of the government, the German Science Council and the University itself and decide what we can learn and what can need to avoid bettering our country's practice.

\subsection{Excellence Strategy-the Government}

The aim of the Excellence Strategy is to strengthen Germany's position as an outstanding place for research in the long term and further improve its international competitiveness.

Decisions on draft proposals and full proposals in the Excellence Strategy are made by the Committee of Experts and the Excellence Commission.

The Committee of Experts consists of 39 members with proven research track records who represent the entire range of academic disciplines. In addition, they have extensive experience in international settings, in university management, in teaching or in the private sector.

The Chair of the German Council of Science and Humanities and the President of the DFG are non-voting members of the committee and preside over it.

The Excellence Commission consists of the Committee of Experts and the government ministers responsible for research at the federal and state levels.

\subsection{The Scientific research evaluations of The German Council (WR)}

The German Science Council (WR) is dedicated to the evaluation of scientific research performance in universities and research institutions in Germany. It was founded in 1957, referring to the first German organization that surveys the scientific research of Germany and provides suggestions for federation and state governments on scientific research funding. The council mainly researches the development of scientific research system, especially in universities and reforms policies of scientific research and universities. Since the 1980s, the Council has established evaluation system of scientific research performance and has formed scientific evaluation system according to evaluation, promotion procedures and research rank as well as innovation approach.

German scientific committee pays great attention to the construction of routines for scientific achievements assessment. It believes that routines for scientific achievements assessment have a strong impact on scientific practice and in order for good scientific practice a rational and effective routine for scientific achievements assessment must be constructed. In "Recommendations for Scientific Achievements Assessment and management of research performance in 2011", the purpose of the assessing and managing 
research performance is to facilitate and encourage good research.

The Council requires evaluation organizations to publicize evaluation criterions and methods, channels and procedures as soon as possible. Evaluation data derive from stable and authoritative international open publications. They carry out pertinent peer review on evaluation objects through quantitative analysis and publicize the results. The period of evaluation on universities and other scientific research institutions is five to ten years per time. [3] The research evaluation of the Council bases on procedures of peer review and principles of scientific evaluation. The results are qualitative evaluation on universities and academic institutions and consist of five grades, namely excellent, good, medium, satisfactory and dissatisfactory. The evaluation results have nothing to do with scientific research funds and only provide references for universities and academic institutions in strategic decision-making. [4]

The German scientific committee's research evaluation procedures for universities and scientific research institutions define the research branches of the evaluated subjects according to the characteristics of the disciplines. The evaluation standard and evaluation index systems are determined by the experts of the evaluation board, and the evaluation methods and evaluation results are publicly announced. The evaluation cycle of humanities and social sciences in German universities is relatively long, generally taking 5-10 years as the cycle of scientific research evaluation in universities. Humanities and social science research use different research evaluation index system.

\subsection{The Practice of the Scientific Research Evaluation in Humanities and Social Sciences of German Universities}

The German Science Council published scientific evaluation reports on the national sociology and national British and American science research respectively. Then this paper will analyze the same and differences in index indicators in respective discipline from the evaluation subject, evaluation object, evaluation purpose, evaluation Standard and Index System. evaluation method and evaluation result.

Evaluation subject: The evaluation board of the sociology discipline is composed of 16 experts, who were jointly nominated and selected by the German Research Association (DFG), the Fraunhofer Association (FhG), the Helmholtz Association (HGF), and the Leibniz Association (WGL), the Max Planck Association (MPG), the Association of University Conferences (HRK), and the German Social Science Federation (DGS). When selecting an evaluation expert, the regional coverage of sociology research and the international perspective of experts should be taken into consideration.The Anglo-American Research Evaluation Board come from the evaluation board of the methodology and sociology discipline.

Evaluation object: Evaluation Board experts first defined the boundaries between sociology and other sciences by dividing sociology into 25 branches. The experts of the Anglo-American Research and Evaluation Board divide the Anglo-American study into four branches: English linguistics research, English literature and cultural studies, American studies (including cultural geography, media studies, spatial studies, language and literature studies) and English subject teaching methods.

Evaluation purpose: It is important to trying to understand the overall development of the German sociology discipline and British and American research with a view to helping academic institutions to position themselves in the country's strengths and weaknesses, and to confirm whether these evaluation systems and procedures can apply all humanities and social science research evaluations.

\subsection{Evaluation Standard and Index System}

Sociology subject evaluation board experts divide the sociology subject evaluation into three dimensions, research, young scholars training and knowledge transfer, and further subdivided into six measurable standards, specifically research quality, research impact and effect, research efficiency, promoting the promotion and development of young scholars, transfering knowledge to other areas of society, and promoting public understanding of science.

The scientific research evaluation index system of sociology subjects focuses on the evaluation of scientific research output quality and scientific research publishing activities, among which used 9 items as a quantitative index for key evaluation of the number of published professional journals (SSCI, SCI, AHCI, CSA), the number of third-party funded scientists, the absolute number of publications, the total amount of third-party funds, the status of individual third-party funds of teachers, the number of non-German publications, the number of publications outside the journal of sociology, the number of scholarships for doctoral programs, and the appointment of young researchers, etc. At the same time, the submitted publications (ie., representative works) are used as the main qualitative evaluation indicators. The sociological subject evaluation index system includes 12 research evaluation angles and 39 specific quantitative and qualitative evaluation indicators, which are related to the value judgment of the performance of sociology research in colleges and universities with four characteristics. The quality of the first scientific 
research output and scientific research and publication activities are all evaluated using qualitative indicators. The second is to use the background information of university teachers' scientific research and publication work as an index of qualitative evaluation. This shows that Germany pays attention to the continuity and coherence of university teachers' scientific research work, and pays attention to the accumulation of scientific research results. The third is to pay special attention to the cultivation work of the promotion of young scholars by college teachers. The assessment indicators are divided into two aspects: the cultivation of doctoral students and the training of young researchers. The fourth is to mark only the evaluation angle of key evaluations and the indicators of key investigations, with no specific weights being given.

The scientific research evaluation standard of the humanities (British and American Studies) include the four standards: scientific research quality, prestige, research possibilities and the transformation of research results, with particular emphasis on scientific research quality and scientific research reputation, 9 evaluation perspectives, 29 qualitative and quantitative evaluation indicators to specifically evaluate. First, among the 29 evaluation indicators, 8 indicators are quantitative evaluations, and the rest are qualitative evaluations. The quality of scientific research includes qualitative evaluation of output quality, which requires 3 masterpieces, excerpts of no more than 50 pages, and a list of publications for qualitative evaluation; all evaluation indicators of research evaluation standard are qualitative evaluations; this evaluation criterion uses qualitative and quantitative evaluation index. It can be seen that they focused more on qualitative peer review. The second is to attach importance to the cultivating and training of the new forces, accounting for 9 of the 29 evaluation index systems, accounting for $31 \%$ of the total indicators, showing the importance attached to the training of new forces. The third is to use facilities and networks as an evaluation perspective based on the characteristics of language research including three qualitative evaluation indicators. The fourth is the angle of evaluation, but there is no specific weight. Germany's scientific evaluation of sociology is based on peer-evaluated and multi-dimensional research evaluation methods based on qualitative and quantitative. The core standard for the evaluation of scientific research in sociology in Germany is the quality of scientific research. Because of the diversity of published works in sociology and the shortcomings of the data obtained, the evaluation process is based on the various forms of the German Social Science Literature Database (SOLIS) and Cambridge Science Citations. The database (CSA), because of the incomplete data, is mainly based on the peer review method of peer experts.

The evaluation of scientific research in the Anglo-American study uses a qualitative and quantitative combination of peer-evaluated methods based on quantitative to examine 8 quantitative indicators and evaluate 21 qualitative indicators.

\section{EVALUATION RESULTS}

The results of scientific research performance evaluation of the sociology subject are published and divided into 5 levels, excellent, good, fine, passing, and failing, while two reports on the evaluation results of the Anglo-American study were published too. One report describing the subject evaluation report of the subject development is divided into nine evaluation levels. The other report analyzes the background, development status, evaluation process and evaluation results of the British and American research in Germany.

In a comparison of analysis we can see that German university research evaluation subject selects experts to set up a special committee for disciplines. The experts of the committee set the evaluation index system corresponding to the corresponding disciplines from the research performance of the disciplines, and rationally control the scientific evaluation process to avoid the evaluation management of convergence.

The "informed peer review" forms the basis for evaluation decisions, in which the opinion of peers is supported by a certain set of indicators. Reading masterpieces is an important process and step for peer evaluation in humanities and social science scientific research evaluation. In 2017 the German Council published "Peer Review in Higher Education and Research" to demonstrate the enormous importance of peer review for the higher education and research system, and to promote a considered approach to review processes.

The rigor and comprehensiveness of its procedures and systems make the German scientific research evaluation system guarantee the academic quality and development direction of scientific research evaluation in German universities.

Germany attaches great importance to the cultivation of young scholars in the evaluation index system of humanities and social sciences. Such an evaluation index system will inevitably lead German university professors to pay attention to the cultivation and development of young researchers, to cultivate future researchers for the literate humanities and social science research, and to carry forward the cultural functions of colleges and universities. Urich Schmoch et al. pointed out that research training is the intermediate output of research activities. But it is crucial to maintaining the structure of the scientific community. [5] 


\section{SELF-EVALUATION SYSTEM OF SCIENTIFIC RESEARCH IN UNIVERSITIES}

Self-reflexivity: organizations in the scientific system need institutional mechanisms (e.g. reporting systems, benchmarking processes) in order to be extensively informed and able to provide information about themselves. Externally, this is necessary for the sake of accountability and disclosure of their performance, and in the internal perspective in order to enable strategic action, decision-making, learning and development. At universities, evaluations of research and/or teaching form an integral part of internal quality management and are an instrument of quality assurance. [6]

The tenure-track procedure in the Humboldt-Universität zu Berlin provides a reliable and transparent career path to lifelong professorship, and thus aims to bind excellent academics at an early stage and provide them with targeted support. A central tenure board monitors the procedure. [7] Statute of the HumboldtUniversität zu Berlin governing appointments to professorships and tenure tracks and Evaluation criteria and standards for tenure-track procedures was amended and adopted in Jan.2019. The two documents clearly defined the career path to professorship and transparent criteria to quality-controlled evaluation: research; academic teaching; participation in academic self-government; promotion of young researchers; acquisition of personnel management skills. [8]

\section{CONCLUSION}

In the German university humanities and social science research evaluation index system, the use of quantitative and qualitative peer evaluation. It guarantees the core position of the academic community's subjective power in scientific research evaluation, and the experts are recommended by several famous German research institutions and recognized peer review institutions, and are publicly selected worldwide. This also stems from the fact that the evaluation mechanism of peer experts in China is still not perfect, and the construction of evaluation systems such as publicity system and feedback system needs to be strengthened.

In the German universities, the humanities and social sciences are used to classify and evaluate the scientific evaluation index system. German university research evaluation subject selects experts to set up a special committee for disciplines. The experts of the committee set the evaluation index system corresponding to the corresponding disciplines from the research performance of the disciplines, and rationally control the scientific evaluation process to avoid the evaluation management of convergence.
Germany attaches great importance to the cultivation of young scholars in the evaluation index system of humanities and social sciences. Such an evaluation index system will inevitably lead German university professors to pay attention to the cultivation and development of young researchers, to cultivate future researchers for the literate humanities and social science research, and to carry forward the cultural functions of colleges and universities. This is worth learning from.

Although in China's "Opinions on Further Improving the Evaluation of Philosophy and Social Science Research in Higher Education Institutions", the Ministry of Education clearly pointed out that " it is necessary to establish and improve the classification evaluation standard system. It is also necessary to target different evaluation objects such as personnel, projects, institutions, and achievements, different subject areas such as humanities and social sciences, different research types such as basic research and applied countermeasure research, and different forms of research achievements such as papers, books, textbooks, research reports, popular reading materials, and non-paper publications etc., so that it can establish and improve a classification evaluation standard system that conforms to the characteristics of philosophy and social sciences"[9]. Taking teaching into consideration. To counteract the preference of research over teaching in the scientific system, effective incentives for teaching and management mechanisms which aim for a balance between incentives for teaching and research are ungently required at the individual level and at the level of the universities.

\section{REFERENCES}

[1] Zhang Zhe, The Evaluation System Should Reflect the Strengths and Weaknesses of Academic Institutions - Interview with Rena Lange, Head of Research at the German Science Council [N] Chinese Social Sciences Today, 2013-2-25. (in Chinese)

[2] Gesellschaft verstehen - Zukunft gestalten. BMBF-Rahmenprogram für die Geistes- und Sozialwissenschaften (2019-2025)

[3] Research Group for Analysis Report on German Scientific and Technological Innovation, Analysis Report on German Scientific and Technological Innovation [M], Beijing: Science Press, 2014(21): 57-58, 258-262

[4] Zhang Zhe. Evaluation System Should Reflect Quality of Academic Institutions: Interview Verna Lange, Director of German Scientific Committee Research Department [N], Chinese Social Sciences Today, Feb.25, 2013 (419) 
[5] Ulrich Schmoch, Torben Schbert, Dorothea Jansen, Richard Heidler and Regina Von Gortz, How to use indicators to measure scientific performance: a balanced approach, [J]Research Evaluation, 19(1),March 2010;

[6] Gesellschaft verstehen - Zukunft gestalten. BMBF-Rahmenprogram für die Geistes- und Sozialwissenschaften (2019-2025)

[7] https://www.hu-berlin.de/en/forschende-en/tenuretr ack/career-path-humboldt-tenure-track/professorshi ps-with-perspective-1/professorships-with-perspect ive

[8] 02_HU_Catalogue of Criteria_Tenure track procedures.pdf (hu-berlin.de)

[9] Ministry of Education of the People's Republic of China, A Summary of the Institutional Documents of Modern Universities with Chinese Characteristics [M] Beijing: Educational Science Press, 2013: 174. (in Chinese) 